\title{
Erratum zu: Andere Sichtweisen auf Subjektivität
}

Fritz Böhle und Eva Senghaas-Knobloch

\section{Erratum zu: F. Böhle und E. Senghaas-Knobloch (Hrsg.), Andere Sichtweisen auf Subjektivität, https://doi.org/10.1007/978-3-658-27118-3}

Die Originalversion dieses Kapitels wurde revidiert: Typographische Fehler wurden korrigiert und Autorennamen ergänzt. Ein Erratum ist verfügbar unter https:// doi.org/10.1007/978-3-658-27118-3_7 und https://doi.org/10.1007/978-3-65827118-3_9.

Die korrigierten Versionen der Kapitel sind verfügbar unter

https://doi.org/10.1007/978-3-658-27118-3_7

https://doi.org/10.1007/978-3-658-27118-3_9

(C) Springer Fachmedien Wiesbaden GmbH, ein Teil von Springer Nature 2019 